Bryn Mawr College

Scholarship, Research, and Creative Work at Bryn Mawr

College

Psychology Faculty Research and Scholarship

Psychology

2017

\title{
The development of autism spectrum disorders: variability and causal complexity
}

Robert H. Wozniak

Bryn Mawr College, rwozniak@brynmawr.edu

Nina B. Leezenbaum

Jessie B. Northrup

Kelsey L. West

Jana M. Iverson

Let us know how access to this document benefits you.

Follow this and additional works at: http://repository.brynmawr.edu/psych_pubs

Part of the Psychology Commons

\section{Custom Citation}

Wozniak, R. H., Leezenbaum, N. B., Northrup, J. B., West, K. L. and Iverson, J. M. 2017. The development of autism spectrum disorders: variability and causal complexity. Wiley Interdisciplinary Reviews-Cognitive Science 8.1-2: 1-8.

This paper is posted at Scholarship, Research, and Creative Work at Bryn Mawr College. http://repository.brynmawr.edu/psych_pubs/58

For more information, please contact repository@brynmawr.edu. 
The development of autism spectrum disorders: variability and causal complexity

Robert H. Wozniak, ${ }^{1,2 *}$ Nina B. Leezenbaum, ${ }^{2}$ Jessie B. Northrup, ${ }^{2}$ Kelsey L. West ${ }^{2}$ and Jana M. Iverson ${ }^{2}$

The autism spectrum is highly variable, both behaviorally and neurodevelopmentally. Broadly speaking, four related factors contribute to this variability: (1) genetic processes, (2) environmental events, (3) gene $\times$ environment interactions, and (4) developmental factors. Given the complexity of the relevant processes, it appears unlikely that autism spectrum atypicalities can be attributed to any one causal mechanism. Rather, the development of neural atypicality reflects an interaction of genetic and environmental risk factors. As the individual grows, changes in neural atypicality, consequent variation in behavior, and environmental response to that behavior may become linked in a positive feedback loop that amplifies deviations from the typical developmental pattern. () 2016 Wiley Periodicals, Inc.

How to cite this article:

WIREs Cogn Sci 2016. doi: 10.1002/wcs.1426

\section{INTRODUCTION}

$\mathrm{T}$ he autism spectrum consists of a wide range of mental and behavioral atypicalities ${ }^{a}$ that usually appear early in childhood, change with development, and continue to manifest themselves throughout life. Individuals said to be 'on the autism spectrum' typically receive a diagnosis of autism spectrum disorder (ASD) based on a series of criteria developed by the American Psychiatric Association. These criteria are: (1) 'persistent deficits in social communication and social interaction across multiple contexts...'; (2) 'restricted, repetitive patterns of behavior, interest, or activities...'; (3) the presence of atypicalities 'in the early developmental period...'; (4) 'clinically significant impairment in social, occupational, or other important areas of current functioning'; and (5) 'disturbances ... not better explained by

*Correspondence to: rwozniak@brynmawr.edu

${ }^{1}$ Department of Psychology, Bryn Mawr College, Bryn Mawr, PA, USA

${ }^{2}$ Department of Psychology, University of Pittsburgh, Pittsburgh, PA, USA

Conflict of interest: The authors have declared no conflicts of interest for this article. intellectual disability ... or global developmental delay'. ${ }^{2}$ Although these criteria might appear to be narrow enough to define a relatively homogeneous entity, they are not. Because DSM criteria can be met in widely differing ways, there is considerable variation among those with the diagnosis. In this article, we will first describe this variability and then discuss some of what we know about the causal complexity that underlies it.

\section{WIDE VARIATIONS AMONG THOSE WITH AN ASD DIAGNOSIS}

Much of the variability in ASD derives from the fact that the diagnostic criteria are complex and change with development. We consider each criterion in turn.

- Because social communication and social interaction occur in many different ways from infancy to adulthood, 'persistent deficits' in this area may include any or all of the following: atypical eye gaze, lack of gestural communication, overly neutral or exaggerated facial expression, impairment in use of language for 
reciprocal communication, problems initiating social interaction, sharing thoughts or feelings, or responding to social cues, or difficulties in developing, understanding, and maintaining relationships with others. Some individuals with ASD avoid eye contact, rarely smile or frown, and do not gesture or speak. Others develop some productive speech and language comprehension, but have great difficulty in using their language skills to interact socially. Still others are highly verbal but have difficulty utilizing the subtle nonverbal cues that regulate communicative exchange, facilitate fluent interaction, and promote the establishment and maintenance of relationships.

- 'Restricted repetitive patterns of behavior, interest, and activities' may include simple motor stereotypies such as hand and arm flapping or rocking back and forth, repetitive use of objects, involuntary repetition of another's vocalizations, resistance to change in routines or rituals, extreme preoccupation with particular objects or events, or rigidity of thinking. This criterion can be met by hypersensitivity to sound or indifference to pain, heat, or cold. Some individuals with ASD are fascinated with objects that spin, imitate verbatim the speech of others, become agitated when a bedtime routine is altered, and find it difficult to adjust their own actions to the demands of changing situations. Others become engrossed in the movement of running water, the sound of a vacuum cleaner, or the sound and motion of a flushing toilet. Still others may be overwhelmed by the sounds and sights of a department store or insensitive to the temperature of their bath water.

- The degree to which these behaviors are observed 'in the early developmental period' is similarly variable. The emergence of ASD has traditionally been described as occurring in one of two ways ${ }^{2}$ : (1) early onset, in which symptoms begin to appear by or before the end of the first year and become more obvious with age; and (2) regressive, in which children appear to develop well within the norm during the first year or two, then lose already-acquired skills and begin to exhibit the atypicalities characteristic of ASD. Recently, however, it has become clear that this dichotomy is too simple. Just as there are wide variations in autistic behavior, there are wide variations in the shapes of individual ASD developmental trajectories. Indeed, as Ozonoff et al. pointed out, ${ }^{2}$ there are in fact 'many intermediate phenotypes containing mixed features and varying degrees of early deficits, subtle diminishments, failures to progress, and frank losses...' (p. 325).

Not surprisingly, therefore, the age at which children receive a definitive diagnosis of ASD (rarely before age two and a half and frequently later ${ }^{3}$ ) is also widely variable. This not only reflects the impact of variation in trajectory shape on diagnosis, it also reflects the fact that many diagnosis-relevant behaviors (e.g., difficulty using language for reciprocal communication, problems sharing thoughts or feelings, rigidity of thought) cannot be observed until children are older. This has led to work focused on identifying markers in infancy that might correctly predict a later ASD diagnosis.

While the evidence for behavioral signs of ASD in the second year is generally strong, ${ }^{4}$ the search for infant markers during the first year has had very limited success. This may possibly be because researchers have been looking in the wrong place. ${ }^{5}$ Given the standard characterization of ASD in terms of impairments in social communication and social interaction, attempts to identify early infant predictors of later diagnosis have tended to focus on proto-social and communicative behaviors. Unfortunately, infants later receiving an ASD diagnosis have generally been found to be indistinguishable from typically developing controls during the first year. This has been true for variables such as frequency of gaze to faces, shared smiles, socially directed vocalizations, ${ }^{6}$ scanning of complex social scenes, ${ }^{7}$ and affective responsivity in face-to-face interaction. ${ }^{8}$ Findings such as these have led to the idea that ASD may first emerge not in the social and communicative domains but in lower level sensory and motor processes ${ }^{9}$ and/or in the general mechanisms by which infants integrate perceptual, attentional, motor, and social information. ${ }^{5}$ While there is some evidence for this in reported atypicalities in visual luminance contrast sensitivity, ${ }^{10}$ visual orienting latencies, ${ }^{11}$ and postural symmetry, ${ }^{12}$ research in these areas is just beginning; and it is probably still fair to say that infant onset of ASD (within Year 1) remains an assumption (for a review, see Ref 13).

- The fourth criterion, 'clinically significant impairment in social, occupational, or other important areas of current functioning,' is extraordinarily general and subjective. By the time typically developing children are in school, for example, they are generally able to dress and undress themselves, button an overcoat, and 
brush hair or teeth. By contrast, even some adolescent and adult autistics ${ }^{b}$ cannot carry out these everyday tasks without constant supervision and assistance. Others are able to function quite effectively in such tasks but lack the speech needed to communicate thoughts, interests, or even needs. Still others have good verbal skills but find it difficult if not impossible to make friends or to approach a stranger to ask a question. Many autistics cannot work; others function well in customized or sheltered employment; and still others are successful in holding jobs, sometimes very high-level jobs, in the community.

- The final criterion, that atypicalities are 'not better explained by intellectual disability or global developmental delay' is of little value as a specific diagnostic marker. Cognitive impairment is characteristic of a significant proportion (but by no means all) of the ASD population and ranges widely in severity. Developmental delay is similarly widespread among those with ASD and, in terms of the psychological processes affected, variable both among and even within individuals.

In short, autistics vary widely in diagnosisrelevant characteristics. They also vary in how and when in development these characteristics emerge, the degree to which they impact daily function, the areas of function that they impact, and ultimate diagnostic outcome. Furthermore, while ASD is typically thought to be a lifelong condition, a small subgroup of individuals not only eventually lose their autism specific symptoms and diagnosis, but become virtually indistinguishable from typically developing children on a variety of socialization, communication, and language measures. ${ }^{15}$

All of this variability should not be surprising. First, of course, given the numerous and complex processes (e.g., neurogenesis, migration, regionalization, synaptogenesis, synaptic pruning, and changes in short- and long-range neural connectivity) involved in neural development, it is apparent that atypicality could, in principle, arise in a wide variety of ways. Second, although atypical mental and behavioral characteristics directly reflect atypical neural development, this is by no means a unidirectional relationship. As atypical characteristics are expressed in the individual's developing interactions with a constantly changing social and physical environment, experience is likely to be atypical; and such experience, over the course of the lifespan, provides a major source of input for continued neural development. The processes by which the nervous system and behavior develop and change throughout life, in other words, are bidirectional: the nervous system influences developing behavior and behavior influences the developing nervous system.

\section{NEURODEVELOPMENTAL ATYPICALITIES: EXPLANATORY ISSUES}

Before discussing explanatory issues in ASD, it may be useful to distinguish between two related but separate questions of causality. The first has to do with risk factors relevant to the occurrence of the neurodevelopmental and cognitive atypicalities characteristic of ASD however phenotypically expressed in behavior. Roughly speaking, we can distinguish among three categories of such factors: (1) genetic risks; (2) environmental risks; and, because genetic and environmental effects cannot be understood apart from one another (3) gene-environment interactions.

The second has to do with the underlying factors that account for autistic behavior, i.e., for the various phenotypic expressions characteristic of ASD. Roughly speaking again, we can distinguish between two levels of explanation in this regard: (1) neurodevelopmental (theories of the developing structure and function of the brain and nervous system); and (2) cognitive (theories of the developing structure and function of the mind). Examples of the first might include early brain overgrowth, ${ }^{16}$ synaptic underpruning, ${ }^{17}$ over-pruning, ${ }^{9}$ imbalance between excitatation and inhibition, ${ }^{18}$ or impairments in long-range neural connectivity ${ }^{19}$; examples of the second might include deficits in theory of mind ${ }^{20}$ or in executive functioning, ${ }^{21}$ or variations in central coherence. ${ }^{22,23}$

Although the second question is a critically important one, addressing it would require an excursion well beyond the purposes of this essay. The goal here, therefore, is the more limited one of describing the broad categories of factors relevant to the occurrence of ASD and, where evidence exists, exemplifying their likely impact on phenotypic variability.

In addition, as the effects produced by factors in each of these categories is conditioned by-and cannot be fully understood apart from-issues of development, we will conclude by discussing a set of developmental issues likely to be relevant to the explanation of ASD.

\section{Genetic Risk Factors}

There is considerable evidence, both indirect and direct, for a significant degree of genetic risk in 
ASD. ${ }^{24,25}$ Indirect evidence includes the observation that children who have an older sibling with ASD are more than 10 times as likely to have ASD themselves as children in the general population (e.g., see Ref 26). For twins, this rate is much higher. Depending on the study, if one member of a pair of monozygotic twins has an ASD diagnosis, the proband concordance rate (the probability that the other twin will have a diagnosis as well) ranges from .46 to .88 or higher ${ }^{27}$ (for review, see Ref 28 ). Reported proband concordance rates for dizygotic twins, on the other hand, are much lower, ranging from 0 to $.36 .^{29}$ The heritability of ASD is, therefore, substantial. However, it may not be as high (.90 or so) as is typically cited. ${ }^{30}$ Indeed, one recent twin analysis yielded an ASD heritability estimate of .37 for autism and .38 for ASD, with $55 \%$ of the variance attributed to shared environmental factors.

Direct evidence comes from sources employing a variety of approaches. One such approach involves the study of syndromes of known single-gene origin with autistic behavioral characteristics (often called 'syndromic autism, ${ }^{31}$ ). Two of the most widely studied forms of syndromic autism involve Fragile $\times$ Syndrome (involving the FMR1 gene and pathogenic mechanisms affecting synaptic plasticity and neuronal connectivity) and Rett Syndrome (MeCP2 gene, implicated in maintaining neuronal function). While syndromes of this sort provide clear evidence that gene-dependent neuronal pathology can be associated with autistic symptomatology, only a very small proportion of ASD cases (e.g., approximately 3-4\% for Fragile $\times$ and Rett taken together) are syndromic. ${ }^{24}$

Researchers have therefore also evaluated genetic risk for nonsyndromic cases. These are cases in which ASD is the primary diagnosis rather than being secondary to a known genetic syndrome. Two of the most important approaches to assessing genetic risk for nonsyndromic ASD involve studies evaluating gene associations and whole genome linkages. Gene association studies focus on correlations between the occurrence of the ASD phenotype and defined genetic variants. These variants (candidate genes) are often chosen on the basis of a priori hypotheses concerning their probable role in aspects of neurogenesis likely to be relevant to ASD, especially impaired synaptic function or abnormal brain connectivity. In whole genome linkage studies, genetic variation throughout the genome, including rare and common inherited and de novo (present in the child but in neither parent) mutations, is evaluated for links with ASD.
Based on the evidence from almost 20 years of gene association studies, it is clear that ASD is genetically heterogeneous. Not only are there literally hundreds of genes that confer risk for $\mathrm{ASD}^{32}$ (see also the Autism Database at https://gene.sfari.org), no single genetic factor is present in more than a tiny fraction $(1-2 \%)$ of ASD cases. This heterogeneity is also evident in research evaluating whole genome linkages, even for siblings and identical twins. Thus, for example, when scientists sequenced the complete DNA of parents and two ASD-diagnosed siblings to examine de novo mutations, they found that the majority $(69.4 \%)$ of the affected siblings carried different ASD-relevant mutations. ${ }^{33}$ This is consistent with the fact that the kinds and severities of ASDassociated traits that each member of a pair of identical twins manifests may vary widely even when both have received an ASD diagnosis. ${ }^{34}$

Finally, recent analyses have provided evidence for still another mechanism underlying genetic heterogeneity in ASD. While rare inherited and de novo variations together only contribute about $6 \%$ of the genetic liability for ASD, a much larger contribution derives from the influence of common variants. Common variants are inherited variations that are widespread in the general population and that, taken individually, confer only slight risk for ASD. When present in significant numbers in the same individual, however, the total ASD risk that they confer may be substantial (as much as $49 \%{ }^{30}$ ). In short, although genetic risk is a major factor in the etiology of ASD, the potential sources of that risk are many and varied.

\section{Environmental Risk Factors}

As complex as it is, the environment may also be a major source of ASD risk. This could occur, for example, when environmental factors increase the likelihood of de novo genetic mutations by contributing to oxidative DNA damage and/or by interfering with DNA repair mechanisms. ${ }^{35}$ Mutagenic factors of this sort include preconceptual exposure to heavy metals (e.g., mercury, cadmium, and nickel) or chlorinated solvents (e.g., trichloroethylene and vinyl chloride) typically present in industrial pollution. They also include residence in higher latitudes, in cities, or in areas with increased precipitation, factors shown to be associated with reduction in levels of Vitamin D involved in DNA repair and protection against oxidative stress.

Another way in which environmental factors might confer ASD risk is by influencing the way in which genes are expressed during development, a 
process known as 'epigenetic variation.' Recent evidence from animal work and from research in areas such as cancer risk indicate that a variety of higherlevel environmental factors such as diet, acoustic and visual stimulation, stress, exposure to toxicants, and, in humans, tobacco and alcohol use can influence factors modulating gene expression. ${ }^{36,37}$ The powerful role that epigenetic variation can in turn play in the development of ASD is evident, for example, in a study of 50 identical twin pairs varying widely in ASD severity and behavioral characteristics even though they share a genome. Wong et al. examined the entire genome of each individual for a factor (DNA methylation) known to influence gene expression. ${ }^{38}$ Although global levels of DNA methylation were highly correlated between members of twin pairs, large variations in methylation were found between pair members at numerous specific DNA sites. Furthermore, the particular sites at which these variations were found were not generally similar across twin pairs but rather were specific to each individual.

Although we now know that epigenetic mechanisms such as DNA methylation can influence phenotypic variation in ASD and that higher level environmental factors can, in principle, influence gene expression, direct evidence for the impact of higher-level environmental risks in ASD is still relatively limited. Only a small number of such factors have been studied; research findings have frequently been inconsistent; and the precise mechanisms by which these factors are linked to neurodevelopmental atypicalities are for the most part unknown. ${ }^{39}$ In addition, most of the known environmental risk factors are associated with only small increases in ASD risk. One such factor is parental age. Mothers over the age of 35 are approximately 1.5 times more likely than younger mothers to have a child with ASD. For older fathers, the increase in risk is slightly greater, ${ }^{40}$ in part because spontaneous genetic mutations are predominantly paternal in origin. ${ }^{41}$ Complications of pregnancy, including gestational diabetes and gestational bleeding have been linked to increased ASD risk, as has maternal exposure to certain chemical substances such as valproic acid (used to treat epilepsy), psychoactive medications, and pesticides. ${ }^{42}$ Although prenatal viral infection has been thought to relate to a higher risk of ASD, the evidence is mixed, presumably because this association is dependent on many other factors such as the immune status of mother and fetus, amount and type of the virus, and stage of fetal development.

Finally, there are several converging sources of evidence suggesting that prenatal exposure to environmental stress may increase the risk for ASD. Mothers of children with ASD retrospectively report higher stress levels during pregnancy than comparison mothers. ${ }^{43}$ Experimental manipulation of prenatal stress in animals is associated with later ASD-like behaviors (in monkeys ${ }^{44}$ and rodents ${ }^{45,46}$ ). And studies of ASD rates in mothers exposed to naturally occurring stressful events suggest an increase in these rates. One intriguing study of this sort was carried out by Kinney et al., who began by assuming that direct exposure to a major storm during pregnancy, especially one that strikes a vulnerable population, acts as an acute source of stress. ${ }^{47}$ They then employed Louisiana weather data to identify areas of the state affected by severe storms and assessed the relationship between the prevalence of ASD and three levels of storm exposure during pregnancy: high (direct hit and high vulnerability, which the researchers defined as birth in New Orleans), medium (EITHER direct hit and born outside New Orleans OR no direct hit and born in New Orleans), and low (no direct hit and born outside New Orleans). Results indicated a significant increase in ASD prevalence rates from about 4.49 to 6.06 to 13.32 children per 10,000 at low, intermediate, and high levels of exposure respectively.

\section{Gene-Environment $(\mathrm{G} \times \mathrm{E})$ Interactions}

One obstacle to isolating environmental factors linked to ASD is that for every child exposed to a given environmental factor who develops ASD, many others exposed to the same factor do not. This has led scientists to turn to the concept of 'geneenvironment interaction.' In its simplest form, this is the idea that genetic risk factors (genotypes and mechanisms of gene expression) in certain children may make them especially vulnerable to particular types of environmental risks. Atypical neural development is presumed to result when a child with a given genetic vulnerability is exposed to the relevant environmental insult (e.g., a developing child whose genetic makeup is such that the body's ability to process and excrete neurotoxic substances is impaired would be particularly vulnerable to neurotoxins). The converse of this idea is that neither a child who is genetically vulnerable but never exposed to the environmental insult nor a child who is environmentally exposed but not genetically vulnerable will develop the related atypicality. This would explain, for example, why only some children are affected by exposure to potentially harmful environmental events. 
Although the existence of $\mathrm{G} \times \mathrm{E}$ interactions of this type in ASD has received some support from research examining ASD-like behavioral characteristics in animal models, ${ }^{48-52}$ to date there are only a few studies on humans. One such analysis, using a candidate gene approach, examined variation in ASD risk conferred by maternal and child genotypic factors when mothers failed to take prenatal vitamins. ${ }^{53}$ In a second analysis using the same study population and approach, ASD risk was reduced for mothers and children with a specific genotypic variant when mothers took folate during the first month of pregnancy. ${ }^{54}$ And in a third-related analysis, ASD risk was reported to reflect an interaction between a given genotype and exposure to air pollution. ${ }^{55}$ Unfortunately, this research suffers from a number of methodological deficiencies and has not been replicated (for a discussion of the considerable methodological obstacles likely to be encountered in research of this type, see Ref 56).

\section{Developmental Factors}

The fact that potentially hundreds of genetic loci, varying in expression, may confer differing degrees of susceptibility to (or protection from) scores of environmental risk factors makes it clear just how complicated the ASD causal network is likely to be. But there is yet another and perhaps even greater set of complications. The effects of $\mathrm{G} \times \mathrm{E}$ interactions likely depend on when and how in the broader course of development the relevant mechanisms come into play.

Although a number of researchers have argued persuasively for the importance of integrating developmental accounts into the explanation of atypicality, ${ }^{36,57-62}$ only a few first steps have been taken in this regard. Thus, for example, Kinney et al. evaluated ASD prevalence in relation to storm exposure during differing gestational periods, ${ }^{47}$ and Thomas et al. have implemented a neurocomputational model of ASD developmental trajectories (early onset, late onset, and regressive) as a function of variations (onset, rate, and threshold) in a connection pruning mechanism. ${ }^{9}$

Although these first steps are important, the potential of this approach with respect to ASD is still largely untapped. One undoubted reason for this is that, when taken seriously (as it should be), the developmental approach multiplies explanatory complexity by an order of magnitude. A summary of relevant developmental principles distilled from the writings of the authors identified above, taken together with ideas derived from two researchers who devoted their careers to the study of development, ${ }^{63-65}$ make this evident.

\section{Development Is First and Foremost Change over Time}

This may appear like a truism; but its implications for our understanding of variability in ASD are farreaching. To date, the vast majority of ASD research consists of comparisons between those with (or at heightened risk for) ASD and CA- or MA-matched typical (or other clinical) groups on measures collected at a single time point. Even the relatively few longitudinal studies that exist have been focused less on change in phenotypic expression over time and more on the use of data from one or more time points to predict a later outcome (e.g., diagnosis). Yet the phenotypic variability in ASD is not just variation in symptom expression, it is also variability in change in symptom expression over time (both moment-to-moment and over longer durations). Although broad stroke developmental trajectories (early onset, later onset, and regressive) generally reflect the fact that symptomatic expression varies in time, they do little to capture either the time-varying nature of specific symptoms or the way in which moment-to-moment changes influence development over longer spans of time.

\section{Developmental Change Is Change in a System of Interacting Processes That Give Rise to Progressively More Complex Structures}

Development is not just a characteristic of timevarying phenotypic behavior; it is a characteristic of the way in which the interacting processes that give rise to behavioral variation themselves change over time. One particularly clear example of this has been provided by Karmiloff-Smith in her neuroconstuctivist analysis of brain development. ${ }^{60}$ In her view, early neural processes are low-level, relatively general and, although somewhat more relevant to processing one kind of input over others, by no means domainspecific. As these processes function over the course of development in interaction with one another and with progressively more complicated sources of environmental input, they become gradually more domain-specific. In other words, the neural processes contributing to varying typical or atypical phenotypic behavior themselves vary developmentally over the course of postnatal growth.

\section{Development Is Multileveled}

The processes that underlie variation in typical and atypical phenotypic behavior are, of course, not solely neurodevelopmental; they exist at multiple 
levels of analysis operating in an integrated system. In addition to those involved in the formation and operation of neural connections, they include processes of gene expression, cognitive and socioemotional growth, behavioral development, and change in the environmental contexts (e.g., family, peers, classrooms, and cultures) within which development occurs. An understanding of variability in phenotypic expression of ASD will not only require analyses at all of these levels, each complex in its own right, it will require an understanding of the way in which change emerges through cross-level relationships. How, for example, does gene expression influence neural development? How does neural development influence growth in the cognitive and socioemotional bases of behavior? How does changing behavior influence the immediate environmental contexts within which that behavior takes places? And because these influences are bidirectional at all levels of analysis, we must also ask, for example, how typical or atypical behaviors are influenced by the contexts within which they occur. How are the neural, cognitive and socioemotional bases of behavior altered as the individual's behavior changes in context? And how is gene expression altered by environmental factors themselves influenced by behavioral change in context?

\section{Development Is Systemic}

At every level of analysis, the processes operating at that level form interconnected components of higherorder systems. Obvious in gene regulation and expression and neural connectivity, systematicity is equally characteristic of the numerous cognitive and socioemotional functions that contribute to behavior. One implication of the componential relationships among processes is that components may develop at varying rates and take varying forms at different points in development. This raises at least two issues for a developmental approach to understanding phenotypic variability. The first has to do with the relative timing of development across component processes. In typical development, this timing is presumed be relatively synchronous with all components changing appropriately in relationship to one another such that developmental outcomes appear more or less on schedule. In atypical development, however, change in one or more components may be delayed relative to change in others and variations in the form and timing of this asynchrony can have immediate and downstream effects on the pattern of emergence of phenotypic outcomes. The second involves a characteristic of development that Kagan ${ }^{65}$ labeled 'heterotypic continuity.' This has to do with the fact that early processes (e.g., those involved in the emergence of fear of strangers) may be continuous with later processes (e.g., those involved in concept formation) with which they have no obvious surface similarity because they are both implementations, albeit at different points in development, of the same underlying component process (e.g., ability to distinguish small variations from prototypes). The implication of heterotypic continuity for an understanding of ASD symptom expression is that phenotypic variability may well reflect an underlying developmental continuity.

\section{Development Occurs through Reciprocal Organism $\times$ Environment Interactions}

As is evident from the previous discussion, at all levels of analysis, variation in developmental processes is best understood as a joint function of characteristics of the organism and characteristics of the environment in interaction. Here the term 'interaction' is used to emphasize the fact that in a developing system, the relationship between two variables almost always varies as a function of values taken on by other (sometimes many other) contextual variables.

Two very different examples may suffice to make this point. The first is a high-level psychological example from Bronfenbrenner's ecological theory of development. ${ }^{64}$ In Bronfenbrenner's view, the effect on developmental outcomes of each of the many variables that describe the individual (e.g., IQ, temperament, physical attractiveness, sociality, curiosity, and passivity) will depend on characteristics of the environmental contexts (e.g., family, peer group, classroom, and culture) within which the individual develops; and, conversely, the effect of environmental variables (e.g., parental support, peer acceptance, and quality of teaching) on outcome will depend on characteristics of the developing individual. What is effective teaching, for example, for a curious child may not be effective teaching for a passive child.

The second example is taken from Gottlieb's ${ }^{36}$ argument for probabilistic epigenesis. There he describes research indicating that a known polymorphism in the serotonin transporter gene (5-HTT) was associated with lower levels of serotonin (and hence higher levels of impulsive aggression) in peer- but not in mother-reared monkeys. In Gottlieb's view, in other words, phenotypic outcomes depend on an interaction between genetic mechanisms and relevant life experiences.

Finally, of course, both the individual and the environment are themselves complex dynamic systems. Development, in other words, is an evolving 
process of organism-environment interaction where both the organism and the environment are themselves systems of interacting and evolving processes.

\section{CONCLUSION}

ASD is characterized by phenotypic behavioral atypicalities emerging in varied forms and according to different developmental trajectories. The causal nexus underlying the emergence of these atypicalities is exceptionally complex. It may include one but probably many developmentally varying pathological mechanisms. These mechanisms may be atypical variations on normal developmental processes or normal processes unfolding with developmentally inappropriate timing. Interacting over time with individual and developmental differences in exposure to factors conferring genetic and environmental risk, these mechanisms may operate to produce variations in the timing of development and atypicality in behavior. Over the course of development, the effects of these interactions may come to extend to domains well beyond that of the original atypicality. Finally, and importantly, delayed development and/or atypical behavior are likely in turn to lead to atypical experiences and interactions with the postnatal environment. An infant who rarely smiles or makes eye contact, a child who tantrums uncontrollably when small changes are introduced into a routine, or a child who insists on spending long hours sitting in the car because he is fascinated by cars is not likely to gain the experiences or elicit the responses from caregivers that are typical of normal development. As the child grows, neural, cognitive, and socioemotional atypicalities, consequent variation in behavior, and environmental responses to that behavior can become linked in a positive feedback loop that reinforces and amplifies deviations from the typical developmental pattern. Given the complexity of this process, it is little wonder that there is such wide behavioral variability among those who receive an ASD diagnosis.

\section{NOTES}

${ }^{a}$ For many, ASD equates with significant, sometimes severe decrement in function. For these individuals, ASD is, as it is for the DSM-5, a 'neurodevelopmental disorder,' one that science should strive to understand, prevent, and remediate. For others, however, ASD is viewed as a form of neurodiversity (cf., http://autismdigest.com/neurodiversity/). For these individuals, ASD is neither a scientific puzzle to be solved, nor a disorder to be prevented, but a lifestyle to be celebrated. To accommodate both views, we prefer and will here use the phrase 'neurodevelopmental atypicality' rather than 'neurodevelopmental disorder.' That said, however, most of the research on ASD has been carried out within a medical/disorder model and will therefore be described in such terms.

${ }^{b}$ We follow Gernsbacher et al. ${ }^{14}$ in employing the term 'autistic/s' rather than 'person/s with autism' because the former is the term by which autistic individuals prefer to be called.

\section{ACKNOWLEDGMENTS}

This study was supported by a grant from the National Institutes of Health (R01 HD073255) to JMI and a Ruth L. Kirchstein National Research Service Award (F31 DC014614-02) to JBN.

\section{REFERENCES}

1. Association AP. Diagnostic and Statistical Manual of Mental Disorders (DSM-5). 5th ed. Arlington, VA: Association AP; 2013.

2. Ozonoff S, Heung K, Byrd R, Hansen R, HertzPicciotto I. The onset of autism: patterns of symptom emergence in the first years of life. Autism Res 2008, $1: 320-328$.

3. Mandell DS, Novak MM, Zubritsky CD. Factors associated with age of diagnosis among children with autism spectrum disorders. Pediatrics 2005, 116:1480-1486.

4. Zwaigenbaum L, Bryson S, Garon N. Early identification of autism spectrum disorders. Behav Brain Res 2013, 251:133-146.
5. Elsabbagh M, Johnson MH. Autism and the social brain: the first-year puzzle. Biol Psychiatry 2016, 80:94-99.

6. Ozonoff S, Iosif AM, Baguio F, Cook IC, Hill MM, Hutman T, Rogers SJ, Rozga A, Sangha S, Sigman M, et al. A prospective study of the emergence of early behavioral signs of autism. I Am Acad Child Adolesc Psychiatry 2010, 49:256-266, e251-e252.

7. Elsabbagh M, Bedford R, Senju A, Charman T, Pickles A, Johnson MH, Team B. What you see is what you get: contextual modulation of face scanning in typical and atypical development. Soc Cogn Affect Neurosci 2014, 9:538-543.

8. Young GS, Merin N, Rogers SJ, Ozonoff S. Gaze behavior and affect at 6 months: predicting clinical 
outcomes and language development in typically developing infants and infants at risk for autism. Dev Sci 2009, 12:798-814.

9. Thomas MS, Davis R, Karmiloff-Smith A, Knowland VC, Charman T. The over-pruning hypothesis of autism. Dev Sci 2016, 19:284-305.

10. McCleery JP, Allman E, Carver LJ, Dobkins KR. Abnormal magnocellular pathway visual processing in infants at risk for autism. Biol Psychiatry 2007, 62:1007-1014.

11. Elison JT, Paterson SJ, Wolff JJ, Reznick JS, Sasson NJ, Gu H, Botteron KN, Dager SR, Estes AM, Evans AC, et al. White matter microstructure and atypical visual orienting in 7-month-olds at risk for autism. Am I Psychiatry 2013, 170:899-908.

12. Esposito G, Venuti P, Maestro S, Muratori F. An exploration of symmetry in early autism spectrum disorders: analysis of lying. Brain Dev 2009, 31:131-138.

13. Jones EJ, Gliga T, Bedford R, Charman T, Johnson MH. Developmental pathways to autism: a review of prospective studies of infants at risk. Neurosci Biobehav Rev 2014, 39:1-33.

14. Gernsbacher MA, Stevenson JL, Khandakar S, Goldsmith HL. Why does joint attention look atypical in autism. Child Dev Perspect 2008, 2:38-45.

15. Fein D, Barton M, Eigsti IM, Kelley E, Naigles L, Schultz RT, Stevens M, Helt M, Orinstein A, Rosenthal M, et al. Optimal outcome in individuals with a history of autism. J Child Psychol Psychiatry 2013, 54:195-205.

16. Courchesne E, Pierce K. Brain overgrowth in autism during a critical time in development: implications for frontal pyramidal neuron and interneuron development and connectivity. Int J Dev Neurosci 2005, 23:153-170.

17. Frith C. Is autism a disconnection disorder? Lancet Neurol 2004, 3:577.

18. LeBlanc JJ, Fagiolini M. Autism: a "critical period" disorder? Neural Plast 2011, 2011:921680.

19. Just MA, Cherkassky VL, Keller TA, Kana RK, Minshew NJ. Functional and anatomical cortical underconnectivity in autism: evidence from an fMRI study of an executive function task and corpus callosum morphometry. Cereb Cortex 2007, 17:951-961.

20. Baron-Cohen S. Mindblindness: An Essay on Autism and Theory of Mind. Cambridge, MA: MIT Press; 1995.

21. Ozonoff S, Pennington BF, Rogers SJ. Executive function deficits in high-functioning autistic individuals: relationship to theory of mind. I Child Psychol Psychiatry 1991, 32:1081-1105.

22. Happe F. Autism: cognitive deficit or cognitive style? Trends Cogn Sci 1999, 3:216-222.
23. Frith U, Happe F. Autism: beyond "theory of mind". Cognition 1994, 50:115-132.

24. Miles JH. Autism spectrum disorders-a genetics review. Genet Med 2011, 13:278-294.

25. Jeste SS, Geschwind DH. Disentangling the heterogeneity of autism spectrum disorder through genetic findings. Nat Rev Neurol 2014, 10:74-81.

26. Ozonoff S, Young GS, Carter A, Messinger D, Yirmiya N, Zwaigenbaum L, Bryson S, Carver LJ, Constantino JN, Dobkins K, et al. Recurrence risk for autism spectrum disorders: a Baby Siblings Research Consortium study. Pediatrics 2011, 128:e488-e495.

27. Lichtenstein P, Carlstrom E, Rastam M, Gillberg C, Anckarsater $\mathrm{H}$. The genetics of autism spectrum disorders and related neuropsychiatric disorders in childhood. Am J Psychiatry 2010, 167:1357-1363.

28. Ronald A, Hoekstra RA. Autism spectrum disorders and autistic traits: a decade of new twin studies. Am J Med Genet B Neuropsychiatr Genet 2011, 156B:255-274.

29. Hallmayer J, Cleveland S, Torres A, Phillips J, Cohen B, Torigoe T, Miller J, Fedele A, Collins J, Smith K, et al. Genetic heritability and shared environmental factors among twin pairs with autism. Arch Gen Psychiatry 2011, 68:1095-1102.

30. Gaugler T, Klei L, Sanders SJ, Bodea CA, Goldberg AP, Lee AB, Mahajan M, Manaa D, Pawitan Y, Reichert J, et al. Most genetic risk for autism resides with common variation. Nat Genet 2014, 46:881-885.

31. Caglayan AO. Genetic causes of syndromic and nonsyndromic autism. Dev Med Child Neurol 2010, 52:130-138.

32. Iossifov I, O'Roak BJ, Sanders SJ, Ronemus M, Krumm N, Levy D, Stessman HA, Witherspoon KT, Vives L, Patterson KE, et al. The contribution of de novo coding mutations to autism spectrum disorder. Nature 2014, 515:216-221.

33. Yuen RK, Thiruvahindrapuram B, Merico D, Walker S, Tammimies K, Hoang N, Chrysler C, Nalpathamkalam T, Pellecchia G, Liu Y, et al. Wholegenome sequencing of quartet families with autism spectrum disorder. Nat Med 2015, 21:185-191.

34. Ronald A, Happe F, Bolton P, Butcher LM, Price TS, Wheelwright S, Baron-Cohen S, Plomin R. Genetic heterogeneity between the three components of the autism spectrum: a twin study. J Am Acad Child Adolesc Psychiatry 2006, 45:691-699.

35. Kinney DK, Barch DH, Chayka B, Napoleon S, Munir KM. Environmental risk factors for autism: do they help cause de novo genetic mutations that contribute to the disorder? Med Hypotheses 2010, 74:102-106.

36. Gottlieb G. Probabilistic epigenesis. Dev Sci 2007, 10:1-11. 
37. Mathers JC, Strathdee G, Relton CL. Induction of epigenetic alterations by dietary and other environmental factors. Adv Genet 2010, 71:3-39.

38. Wong CC, Meaburn EL, Ronald A, Price TS, Jeffries AR, Schalkwyk LC, Plomin R, Mill J. Methylomic analysis of monozygotic twins discordant for autism spectrum disorder and related behavioural traits. Mol Psychiatry 2014, 19:495-503.

39. Gardener H, Spiegelman D, Buka SL. Prenatal risk factors for autism: comprehensive meta-analysis. Br J Psychiatry 2009, 195:7-14.

40. Hultman CM, Sandin S, Levine SZ, Lichtenstein P, Reichenberg A. Advancing paternal age and risk of autism: new evidence from a population-based study and a meta-analysis of epidemiological studies. Mol Psychiatry 2011, 16:1203-1212.

41. O'Roak BJ, Vives L, Girirajan S, Karakoc E, Krumm N, Coe BP, Levy R, Ko A, Lee C, Smith JD, et al. Sporadic autism exomes reveal a highly interconnected protein network of de novo mutations. Nature 2012, 485:246-250.

42. Grabrucker AM. Environmental factors in autism. Front Psychiatry 2012, 3:118.

43. Beversdorf DQ, Manning SE, Hillier A, Anderson SL, Nordgren RE, Walters SE, Nagaraja HN, Cooley WC, Gaelic SE, Bauman ML. Timing of prenatal stressors and autism. J Autism Dev Disord 2005, 35:471-478.

44. Clarke AS, Soto A, Bergholz T, Schneider ML. Maternal gestational stress alters adaptive and social behavior in adolescent rhesus monkey offspring. Infant Behav Dev 1996, 19:451-461.

45. Weinstock M. Does prenatal stress impair coping and regulation of hypothalamic-pituitary-adrenal axis? Neurosci Biobehav Rev 1997, 21:1-10.

46. Weinstock M. Can the behaviour abnormalities induced by gestational stress in rats be prevented or reversed? Stress 2002, 5:167-176.

47. Kinney DK, Miller AM, Crowley DJ, Huang E, Gerber E. Autism prevalence following prenatal exposure to hurricanes and tropical storms in Louisiana. $J$ Autism Dev Disord 2008, 38:481-488.

48. Pletnikov MV, Rubin SA, Vogel MW, Moran TH, Carbone KM. Effects of genetic background on neonatal Borna disease virus infection-induced neurodevelopmental damage. II. Neurochemical alterations and responses to pharmacological treatments. Brain Res 2002, 944:108-123.

49. Pletnikov MV, Rubin SA, Vogel MW, Moran TH, Carbone KM. Effects of genetic background on neonatal Borna disease virus infection-induced neurodevelopmental damage. I. Brain pathology and behavioral deficits. Brain Res 2002, 944:97-107.

50. Abazyan B, Nomura J, Kannan G, Ishizuka K, Tamashiro KL, Nucifora F, Pogorelov V, Ladenheim B, Yang C, Krasnova IN, et al. Prenatal interaction of mutant DISC1 and immune activation produces adult psychopathology. Biol Psychiatry 2010, 68:1172-1181.

51. Ehninger D, Sano Y, de Vries PJ, Dies K, Franz D, Geschwind DH, Kaur M, Lee YS, Li W, Lowe JK, et al. Gestational immune activation and Tsc2 haploinsufficiency cooperate to disrupt fetal survival and may perturb social behavior in adult mice. Mol Psychiatry 2012, 17:62-70.

52. Lacaria M, Spencer C, Gu W, Paylor R, Lupski JR. Enriched rearing improves behavioral responses of an animal model for CNV-based autistic-like traits. Hum Mol Genet 2012, 21:3083-3096.

53. Schmidt RJ, Hansen RL, Hartiala J, Allayee $H$, Schmidt LC, Tancredi DJ, Tassone F, Hertz-Picciotto I. Prenatal vitamins, one-carbon metabolism gene variants, and risk for autism. Epidemiology 2011, $22: 476-485$.

54. Schmidt RJ, Tancredi DJ, Ozonoff S, Hansen RL, Hartiala J, Allayee H, Schmidt LC, Tassone F, HertzPicciotto I. Maternal periconceptional folic acid intake and risk of autism spectrum disorders and developmental delay in the CHARGE (CHildhood Autism Risks from Genetics and Environment) case-control study. Am J Clin Nutr 2012, 96:80-89.

55. Volk HE, Kerin T, Lurmann F, Hertz-Picciotto I, McConnell R, Campbell DB. Autism spectrum disorder: interaction of air pollution with the MET receptor tyrosine kinase gene. Epidemiology 2014, 25:44-47.

56. Kim YS, Leventhal BL. Genetic epidemiology and insights into interactive genetic and environmental effects in autism spectrum disorders. Biol Psychiatry 2015, 77:66-74.

57. Thelen E. The central role of action in typical and atypical development: a dynamic systems perspective. In: Stockman IJ, ed. Movement and Action in Learning and Development: Clinical Implications for Pervasive Developmental Disorders. San Diego, CA: Elsevier Academic Press; 2004, 49-73.

58. Gottlieb G. Normally occurring environmental and behavioral influences on gene activity: from central dogma to probabilistic epigenesis. Psychol Rev 1998, 105:792-802.

59. Karmiloff-Smith A. Development itself is the key to understanding developmental disorders. Trends Cogn Sci 1998, 2:389-398.

60. Karmiloff-Smith A. Nativism versus neuroconstructivism: rethinking the study of developmental disorders. Dev Psychol 2009, 45:56-63.

61. Sameroff AJ. Developmental systems and psychopathology. Dev Psychopathol 2000, 12:297-312.

62. Thomas MS, Annaz D, Ansari D, Scerif G, Jarrold C, Karmiloff-Smith A. Using developmental trajectories to understand developmental disorders. I Speech Lang Hear Res 2009, 52:336-358. 
63. Bronfenbrenner U. The Ecology of Human Development: Experiments by Nature and Design. Cambridge, MA: Harvard University Press; 1979.

64. Bronfenbrenner U. The ecology of cognitive development: research models and fugitive findings. In:
Wozniak RH, Fischer KW, eds. Development in Context: Acting and Thinking in Specific Environments. Hillsdale, NJ: Erlbaum; 1993.

65. Kagan JK. Change and Continuity in Infancy. New York: Wiley; 1971. 